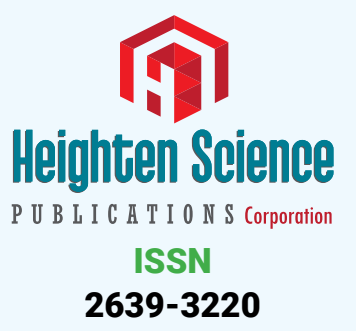

*Address for Correspondence: Dr. Saeed OraeeYazdani, Shohada Tajrish Neurosurgical Center of Excellence, Functional Neurosurgery Research Center, Shohada Tajrish Hospital, Shahid Beheshti University of Medical Sciences, PO box: 1988873554, Tehran, Iran. Email:

Saeed_o_yazdani@sbmu.ac.ir

Submitted: 17 December 2018

Approved: 28 December 2018

Published: 31 December 2018

Copyright: @ 2018 Yazdani SO, et al. This is an open access article distributed under the Creative Commons Attribution License, which permits unrestricted use, distribution, and reproduction in any medium, provided the original work is properly cited

Keywords: Spondyloptosis; Cervical spine; Surgery management

Check for updates
Case Report

\section{A Three approach at one stage to surgical management of Cervical Spondyloptosis after Failed Primary anterior fusion}

\author{
Saeed Oraee-Yazdani*, Maryam Golmohammadi, \\ Mohammadhosein Akhlaghpasand and Maryam Oraee-Yazdani \\ Shohada Tajrish Neurosurgical Center of Excellence, Functional Neurosurgery Research Center, \\ Shohada Tajrish Hospital, Shahid Beheshti University of Medical Sciences, Tehran, Iran
}

\section{Abstract}

A 35-year-old female, known case of complete spinal cord injury, presented with cervical pain and neck deformity that interfere with her physiotherapy and occupational therapy. Two years before admission, she had a car accident which result in a complete quadriplegia. That time at another center, she underwent surgery to anterior cervical fixation of $\mathrm{C} 6-\mathrm{C} 7$ through insertion of cage and plate without corpectomy. Based on current radiologic images, spondyloptosis was detected at the $\mathrm{C} 6-\mathrm{C} 7$ with bilateral locked facet, due to hardware failure. A three approaches in one stage was performed to maintain cervical alignment that includes posterior, anterior and again posterior approach. With this manner, anterior fusion through corpectomy and insertion of expandable cage and plate as same as instrumental posterolateral fusion were done. After surgery, she was pain free and the alignment of cervical spine was maintained so she could come back to ordinary rehabilitation programs.

\section{Introduction}

Spondyloptosis, a rare subtype of spondylolisthesis, is defined as complete dislocation of a superior vertebral body on an inferior one in the coronal and sagittal plane that results from an injury [1-3]. Cervical spondyloptosis is an uncommon event and associated with a complete and irreversible neurological deficit [4]. The usual therapy is reduction and stabilization of the fracture subluxation, typically with combined anterior and posterior fusion. In this article, we present a case of cervical spondyloptosis (C6 on C7) after failure of primary anterior fusion that was stabilized via three approach in one stage.

\section{Case Presentation}

A 35-year-old female, a known case of complete spinal cord injury (SCI), was admitted to neurosurgery department with complaint of neck and shoulder pain, kyphotic neck deformity. Two years ago, she had a car accident and she underwent anterior cervical fixation insertion of cage and plate without corpectomy. After a while, she presented with severe neck pain and kyphotic deformity as she could not perform her ordinary activity including physiotherapy and occupational therapy. After presentation to our neurosurgery department, CT revealed a spondyloptosis of C6 on C7 with bilateral facet lock (Figure 1A,B). Moreover, MRI was obtained to demonstrate the dislocation and assessment of disc and soft tissue.

How to cite this article: Yazdani SO, Golmohammadi M, Akhlaghpasand M, Yazdani MO. A Three approach at one stage to surgical management of Cervical Spondyloptosis after Failed Primary anterior fusion. J Neurosci Neurol Disord. 2018; 2: 098-100. https://doi.org/10.29328/journal.jnnd.1001018 


\section{Operative details}

After anesthesia, the head of patient fixed by three pin Mayfield headrest. At the first stage, the patient was placed at prone position, bilateral facetectomy at the level of C6 and C7 was performed. As second stage, the patient was placed at supine position. Before surgery, to check the possibility of recurrent laryngeal nerve injury through right anterior approach at the first operation, a laryngoscopy was performed in which the absence of paralysis of the vocal cord was proven. At this time, the patient underwent surgery through left side to prevent injury of the esophagus and vessels due to adhesions in the first surgery. After removing failed cage and plate, corpectomy of $\mathrm{C} 6$ and $\mathrm{C} 7$ was performed and expandable cage was inserted in the space and a plate was fixed on the cage at C5 and T1 (Figure 1C,D). All of these procedures performed under guidance of C-Arm. At the final stage, the patient was placed in prone position again, then posterior fusion was performed using lateral mass at the level of $\mathrm{C} 4, \mathrm{C} 5$ and $\mathrm{C} 6$ and pedicle screw at the level of $\mathrm{C} 7$ and T1. Through performing this stages, cervical alignment was maintained. After surgery, neck deformity was resolved and the patient was able to do her ordinary activities and she was pain free.

\section{Discussion}

Spondyloptosis, a rare subtype of spondylolisthesis is a complete coronal and sagittal translation of a superior vertebral body on an inferior one that occurs predominantly in the lumbar part due to motor vehicle accidents and diving injuries [5]. Moreover, there are another causes of spondyloptosis including birth trauma [6], congenital cervical pedicles absence, corticated defect in the pars interarticularis [7], neurofibromatosis and aneurysmal bone cyst of cervical spine [8]. The etiology of spondyloptosis in our patient was car accident. Spondyloptosis of the cervical spine is usually associated with spinal cord injury and presented with myelopathy, radiculopathy, cervical spasm and neck pain which can significantly affect the quality of life. Our patient as a known case of complete spinal cord injury, had kyphotic neck deformity and cervical pain due to failed anterior cervical fixation through cage and plate insertion without corpectomy. In order to relieve her pain and increased her quality of life, a surgical approach was done.

There are different controversial surgical methods to provide a well-aligned, stable spine without causing a new neurological deficit. The most common method is simultaneously anterior and posterior approach (360 degree) at one stage or staged

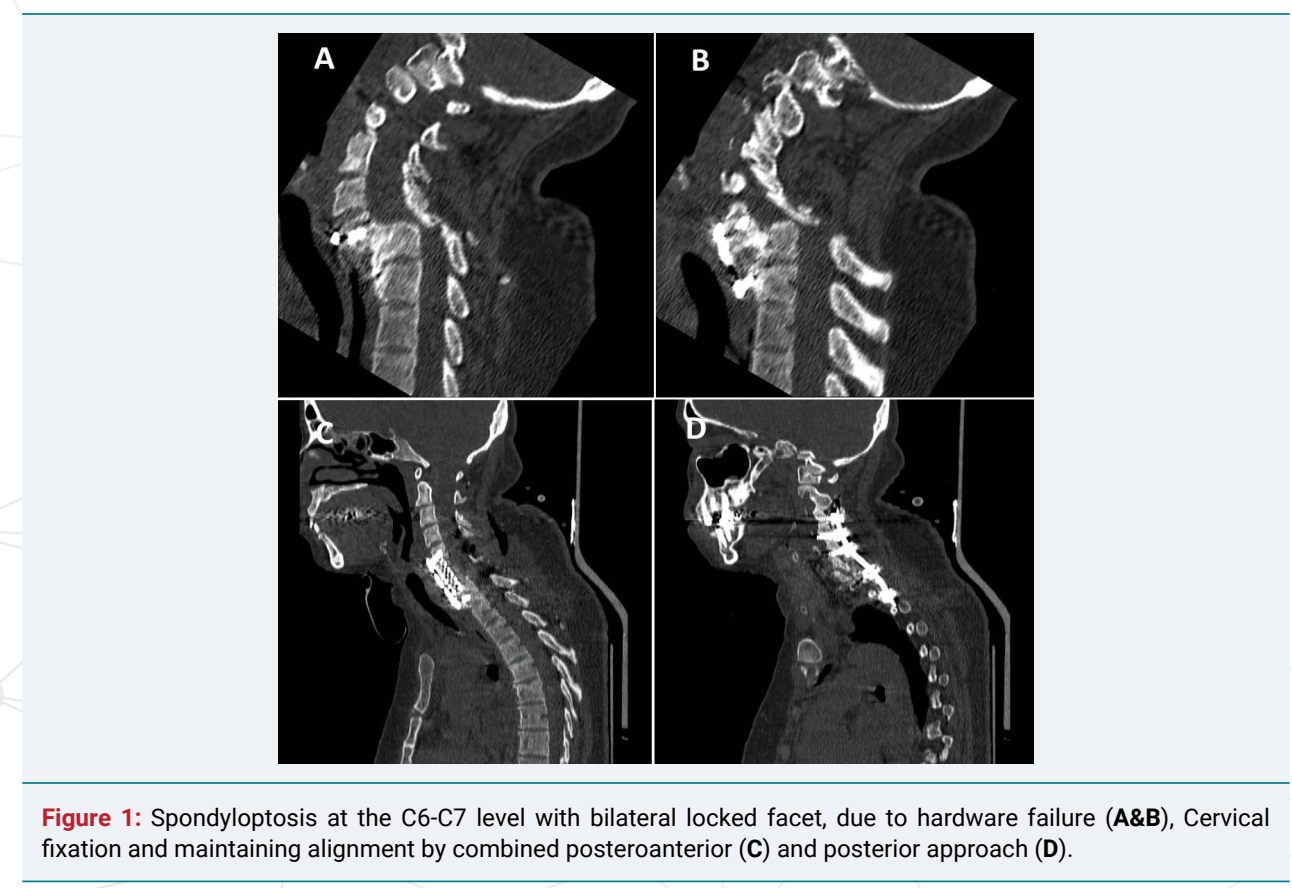


manner. We performed posterior, anterior and again posterior approach (540 degree) to manage the cervical spondyloptosis with regards to failure of primary fusion; we carried out three approach in one stage so there was no need for temporary fixation. Shah et al., have indicated that uninstrumented ventral surgery alone might suffice in selected patients with cervical spondyloptosis [1]. Also Srivastava et al., demonstrated that a limited anterior-only fusion at the spondyloptosis level can provide good longterm results with preservation of other motion segments [9]. Menku et al., reported a case with successful one stage anterior, posterior and anterior correction and fusionstabilization procedure to realigned the spine with extension from $\mathrm{C} 4$ to $\mathrm{C} 7$ without preoperative cervical traction [10]. Similarly, Tumialan et al. represented a patient with traumatic cervical spondyloptosis at the C7-T1 level that underwent anterior and posterior instrumented stabilization.

It seems that in cases of spondyloptosis, decision should be made individually, but anterior and posterior fixation (360 degree), will be a confident method to maintain long term alignment and permanent fusion.

\section{Patient consent}

Informed consent was obtained from the patient to publish the report.

\section{References}

1. Shah KC, Rajshekhar V. Successful management of post-traumatic C7-T1 spondyloptosis with uninstrumented ventral surgery. Surgical neurology. 2004; 62: 431-434. Ref.: https://goo.gl/ZLmEzR

2. Akay K, Ersahin Y, Tabur E. Cervical spondyloptosis: a case report. Minim Invasive Neurosurg. 2002; 45:169-172. Ref.: https://goo.gl/X3RkaA

3. Lee DG, Hwang SH, Lee $\mathrm{CH}$, Kang DH. Clinical experience of traumatic C7-T1 spondyloptosis. J Korean Neurosurg Soc. 2007; 41: 127-129. Ref.: https://goo.gl/K76UUZ

4. Millar T, McConnachie C. Complete fracture-dislocation of the lower cervical spine associated with significant ligamentous disruption of the upper cervical spine: A case of survival without permanent neurological sequelae. Injury Extra. 2007; 38: 317-319. Ref.: https://goo.gl/gy1JMz

5. Acikbas C, Gurkanlar D. Post-traumatic C7-T1 Spondyloptosis in a patient without neurological deficit: a case report. Turkish neurosurgery. 2010; 20: 257-260. Ref.: https://goo.gl/9YDSUZ

6. Bhojraj SY, Shahane SM. Posttraumatic cervical spondyloptosis at C6-7 with late-onset cord compression: a new clinical entity: Case report. Journal of neurosurgery. 1992; 77: 792-794. Ref.: https://goo.gl/UbfKx1

7. Song KC, Cho KS, Lee SB. Congenital defect of the posterior arch of cervical spine: report of three cases and review of the current literature. J Korean Neurosurg Soc. 2010; 48: 294297. Ref.: https://goo.gl/S9bXsP

8. Goffin J, Grob D. Spondyloptosis of the cervical spine in neurofibromatosis: a case report. Spine. 1999; 24: 587-590. Ref.: https://goo.gl/NBSdbz

9. Srivastava SK, Agrawal KM, Sharma AK, Agrawal MD, Bhosale SK, et al. C3-C4 spondyloptosis without neurological deficit-a case report. Spine J. 2010; 10: e16-e20. Ref.: https://goo.gl/KiXBv5

10. Menku A, Kurtsoy A, Tucer B, Oktem I, Akdemir H. The surgical management of traumatic C6-C7 spondyloptosis in a patient without neurological deficits. Minim Invasive Neurosurg. 2004; 47: 242244. Ref.: https://goo.gl/1Gwc7Z 